\title{
Enrichment characteristic of carbon atoms in solid-liquid zone of high carbon steel under different directional solidification rates
}

\author{
Yong Wan ${ }^{1,2,3}$, Shan Gao ${ }^{3}$, Meng-hua Li ${ }^{3}$, Li-qiang Zhang ${ }^{3}$, 'Yong-hong Wen ${ }^{3}$, Ming-ming Song ${ }^{2}$ \\ 1. Anhui Province Key Laboratory of Metallurgical Engineering \& Resources Recycling, Anhui University of Technology, Ma'anshan 243002, \\ Anhui, China \\ 2. The State Key Laboratory of Refractories and Metallurgy, Wuhan University of Science and Technology, Wuhan 430081, China \\ 3. School of Metallurgical Engineering, Anhui University of Technology, Ma'anshan 243002, Anhui, China
}

\begin{abstract}
To reveal the formation mechanism and main influencing factors of C-segregation in high carbon steel under different solidification rates $\left(40,80,160,200\right.$ and $\left.320 \mu \mathrm{m} \cdot \mathrm{s}^{-1}\right)$, the enrichment characteristics of carbon atoms in the solid-liquid zone of Fe- $0.61 \% \mathrm{C}$ steel were studied using a zone melting liquid metal cooling apparatus and electron probe microanalysis. The relationships among micro-segregation of carbon atoms, solid-liquid interface morphology and solidification rate were fully discussed. The results show that large dendrite spacing and a slow-moving dendritic interface create less resistance and more time for the migration of interdendritic carbon atoms to liquid zone. This results in the continuous enrichment of carbon atoms in liquid zone, further expands the solid-liquid temperature range, prolongs the solidification time of molten steel, and causes the formation of carbon micro-segregation at the solidification end as the solidification rate is $40 \mu \mathrm{m} \cdot \mathrm{s}^{-1}$. Conversely, abundant and elongated secondary dendrite arms with small spacing seriously impede the diffusion of interdendritic carbon-rich molten steel to liquid zone. As a result, there is only obvious dendrite segregation, but little difference in the carbon content along the solidification direction as solidification rate exceeds $200 \mu \mathrm{m} \cdot \mathrm{s}^{-1}$.
\end{abstract}

Key words: enrichment characteristic; high carbon steel; solid-liquid zone; carbon atom; dendrite; solidification rate

CLC numbers: TG142.31 Document code: A

Article ID: 1672-6421(2021)05-488-09

\section{Introduction}

High carbon wire rods are mainly used for making a high strength and low relaxation prestressed steel strand. To obtain high tensile strength and ductility of the wire rods, the first priority is to control the central segregation of high carbon steel billet (HCSB), especially carbon segregation (C-segregation), which can easily result in cup-cone type failure during subsequent deformation processing, or premature failure of finished products in service ${ }^{[1-6]}$. To minimize C-segregation of HCSB, a series of optimization techniques, e.g., low temperature casting, intensive cooling in secondary cooling zone, electromagnetic stirring (EMS or EMS+FEMS), soft reduction, etc., have been applied to its continuous

\footnotetext{
*Yong-hong Wen
}

Male, Ph.D, Senior Engineer. Research direction: Quality control of high carbon steel billets. To date, he has published more than 10 academic papers.

E-mail: yonghongwen12@126.com

Received: 2021-01-08; Accepted: 2021-09-06 casting process ${ }^{[7-9]}$. The formation mechanism of C-segregation has been gradually revealed. Beckermann ${ }^{[10]}$ simulated the movement of solute atoms at the solid-liquid interface with a macrosegregation model and indicated that solute atoms were rejected from dendrite and accumulated in the interdendritic melt due to the solubility difference between liquid and solid phases, resulting in the formation of carbon macrosegregation. Eskin et al. ${ }^{[11]}$ investigated the contribution of coarse-cell and finecell grains to $\mathrm{C}$-segregation by direct-chill casting and found that coarse-cell grains were depleted in solute, and the areas of their accumulation contributed to the negative segregation of carbon, while the areas of finecell grains were either enriched in solute or were close to the nominal composition. Zeng et al. ${ }^{[12]}$ conducted plant tests to study the effect of secondary cooling conditions on solidification structure and central macro-segregation in a high-carbon rectangular billet and pointed out that secondary cooling conditions at the solid-liquid interface strongly affected grain 
growth in the mushy zone, and equiaxed grains could prevent the formation of solidification bridges and redistribution of residual solute. Wan et al. ${ }^{[13]}$ studied the distribution of the electromagnetic field at the solidification end and obtained the optimal stirring parameters to uniform cross-sectional carbon concentration of a $\mathrm{Fe}-0.70 \% \mathrm{C}$ steel billet. It is well known that liquid flow and solidification behavior at the solid-liquid interface strongly affect the distribution of carbon content in liquid and solid phases, and thus affect the central C-segregation level of HCSB ${ }^{[14-16]}$. Nevertheless, the relationship between carbon segregation and grain growth at the solid-liquid interface has not been adequately studied, and the effect of cooling condition on the distribution of carbon atoms in solid/liquid phase has also received much less attention.

In the present work, the enrichment characteristic of carbon atoms in the solid-liquid zone of high carbon steel under different solidification rates was investigated. The relationships among $\mathrm{C}$-segregation, solid-liquid interface morphology and solidification rate were discussed, which were beneficial to reveal the formation mechanism and main influencing factors of C-segregation in high carbon steel during solidification.

\section{Experimental procedure}

Directional solidification was performed in a zone melting liquid metal cooling (ZMLMC) apparatus ${ }^{[17]}$. The sample (length $=100 \mathrm{~mm}$, diameter $=7 \mathrm{~mm}$ ) utilized for directional solidification was cut from $\mathrm{Fe}-0.61 \% \mathrm{C}$ steel whose chemical compositions are shown in Table 1 . The sample placed in corundum tube was firstly heated to $1,505{ }^{\circ} \mathrm{C}$ and held for $30 \mathrm{~min}$ at a temperature gradient of $80^{\circ} \mathrm{C} \cdot \mathrm{mm}^{-1}$ by controlling the output power of heating device. Then, the sample was pulled down under a given solidification rate (e.g., 40, 80, 160,200 and $320 \mu \mathrm{m} \cdot \mathrm{s}^{-1}$ ) by controlling the speed of the synchronous motor. When pulled down $30 \mathrm{~mm}$, the sample was quenched rapidly in Ga-In-Sn liquid coolant to preserve the solid-liquid interface morphology. The quenched sample was cut along the center of the longitudinal section and one part (length $=15 \mathrm{~mm}$, width $=7 \mathrm{~mm}$ ) which contained solidliquid interface and solid zone was selected for observation and analysis. The morphologies of the solid-liquid interface were observed with a Leica DMRX model optical microscope (OM) after etching by heat saturated picric acid. The microstructures of longitudinal sections from solid-liquid interface to solid phase were etched by $4 \%$ nital solution, then photographed with a QUANTA400 model scanning electron microscope (SEM). The dendrite arm spacing of sample under a certain solidification rate was measured by the scale function of Adobe Photoshop CS6 software; the average value of 20 dendrite arm spacings was calculated. Longitudinal sections from solid-liquid interface to solid phase were etched by $4 \%$ nital solution then measured the hardness with a MH$5 \mathrm{~L}$ model Vickers hardness tester (VHT). The distribution characteristics of carbon atoms at solid-liquid interface were detected by using the 1720 model electron probe microanalysis (EPMA). To avoid carbon pollution introduced in the sample preparation process as much as possible, the sample under electron probe observation was specially treated with argon ion polishing equipment after grinding and polishing. The step size of mapping analysis was $5 \mu \mathrm{m}$, and the acquisition time of each point was $80 \mathrm{~ms}$. The step size of line analysis was 3 $\mu \mathrm{m}$, and the acquisition time of each point was $2 \mathrm{~s}$. The area ratios of different carbon contents in the electron probe image were counted with Adobe Photoshop CS6 software. Moreover, the $\mathrm{Fe}-\mathrm{C}$ pseudo-binary phase diagram and carbon equilibrium distribution coefficient $k_{\mathrm{C}}\left(k_{\mathrm{C}}=C_{\gamma} / C_{\mathrm{L}}\right.$, where $C_{\gamma}$ is the carbon content in austenite, $\gamma, C_{\mathrm{L}}$ is the carbon content in liquid steel) of high carbon steel under different temperatures were calculated by FactSage 7.2 software.

Table 1: Chemical compositions of Fe- $0.61 \% \mathrm{C}$ steel (mass\%)

\begin{tabular}{ccccccccc} 
C & Si & Mn & S & P & Al & N & Fe \\
\hline 0.61 & 0.22 & 0.55 & 0.005 & 0.010 & 0.001 & 0.0035 & Bal.
\end{tabular}

\section{Results and discussion}

\section{$3.1 k_{\mathrm{c}}$ in solid-liquid zone of high carbon steel}

Figure 1 exhibits the isopleth $\mathrm{Fe}-\mathrm{C}$ section of the phase diagram of Fe-C-Si-Mn-P-S multicomponent system and solid/liquid equilibrium distribution coefficient $k_{\mathrm{C}}$ in the solid-liquid zone of $\mathrm{Fe}-0.61 \% \mathrm{C}$ steel, respectively. It can be seen from Fig. 1(a) that the liquid $\rightarrow \gamma$ transformation temperature gradually reduces as carbon content increases, while the temperature range of solidliquid zone (liquid $+\gamma$ ) apparently increases as carbon content increases, which provides condition for the formation of carbon segregation during solidification ${ }^{[18,19]}$. As shown in Fig. 1(b), the equilibrium solidification interval and liquidus slope are 1400- $1480{ }^{\circ} \mathrm{C}$ and $-73.3{ }^{\circ} \mathrm{C} \cdot \%{ }^{-1}$, respectively. Moreover, the $k_{\mathrm{C}}$ varies from 0.33 at $1,480{ }^{\circ} \mathrm{C}$ to 0.38 at $1,400{ }^{\circ} \mathrm{C}$. The carbon content in liquid obviously increases with decreasing temperature, while the carbon content in austenite slowly increases during the temperature interval between two red dot lines in Fig. 1(b).

\subsection{Solid-liquid interface morphologies of Fe- $0.61 \% \mathrm{C}$ steel under different solidification rates}

Figure 2 illustrates the solid-liquid interface morphologies of $\mathrm{Fe}-0.61 \% \mathrm{C}$ steel corresponding to different solidification rates. It can be seen from Fig. 2 that the morphologies of the solidliquid interface are typical dendrites for solidification rates of $40-320 \mu \mathrm{m} \cdot \mathrm{s}^{-1}$. The morphology of the solid-liquid interface is 

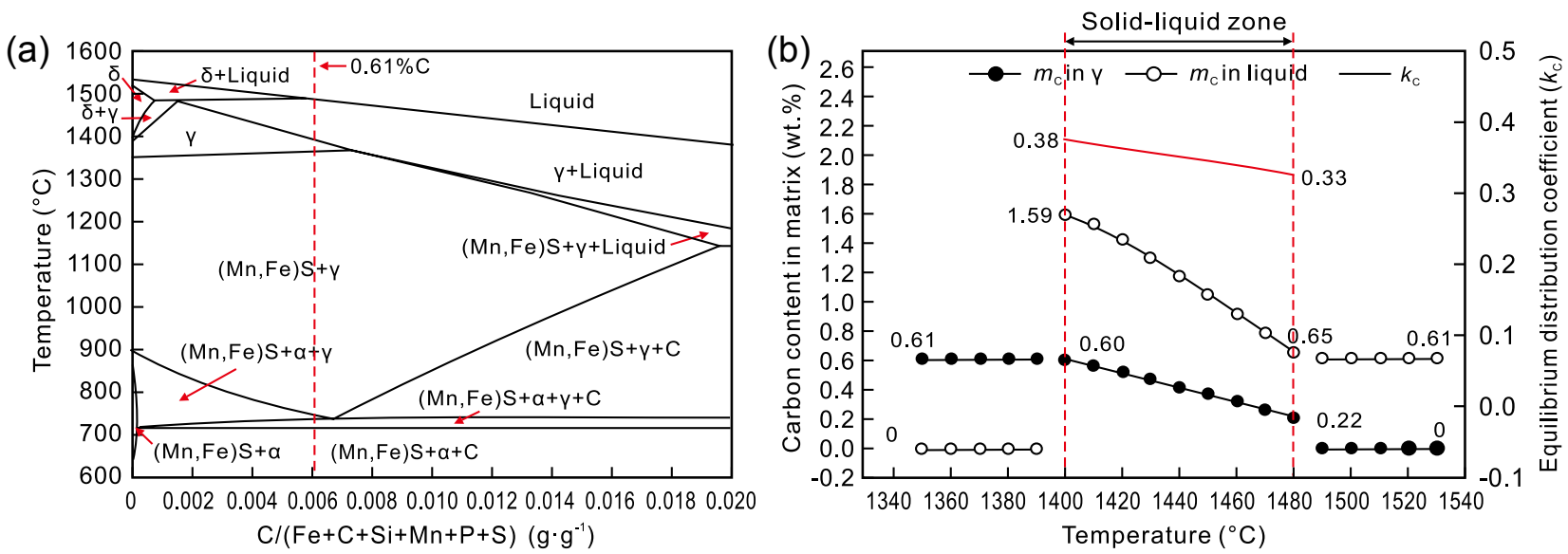

Fig. 1: Calculated isopleth Fe-C section of phase diagram of Fe-C-Si-Mn-P-S multicomponent system (a) and $k_{\mathrm{C}}$ in solid-liquid zone of $\mathrm{Fe}-0.61 \% \mathrm{C}$ steel (b)

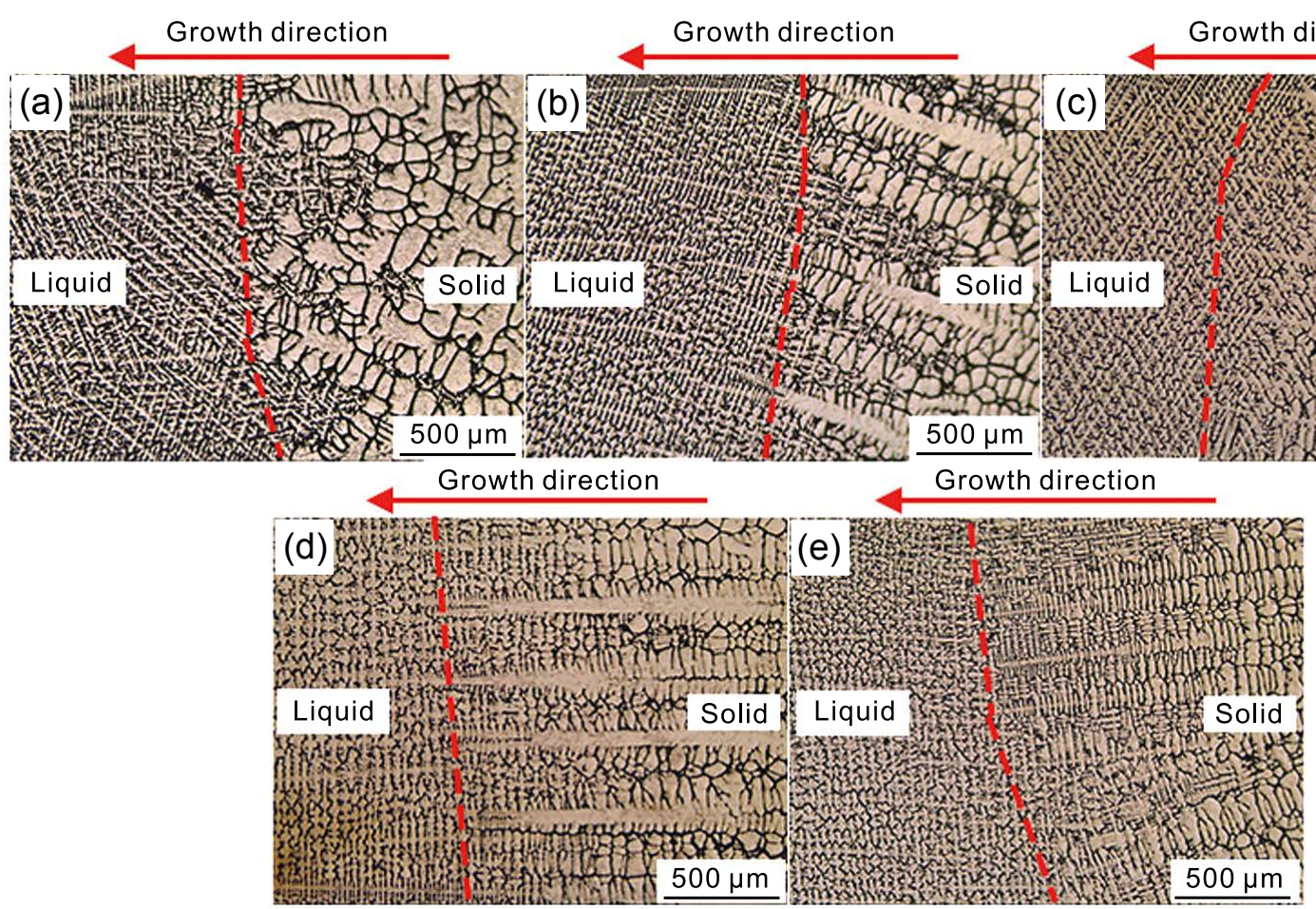

Fig. 2: Solid-liquid interface morphologies of Fe- $0.61 \% \mathrm{C}$ steel under different solidification rates: (a) $40 \mu \mathrm{m} \cdot \mathrm{s}^{-1}$; (b) $80 \mu \mathrm{m} \cdot \mathrm{s}^{-1}$; (c) $160 \mu \mathrm{m} \cdot \mathrm{s}^{-1}$; (d) $200 \mu \mathrm{m} \cdot \mathrm{s}^{-1}$; (e) $320 \mu \mathrm{m} \cdot \mathrm{s}^{-1}$

judged according to Eqs. (1)-(3) ${ }^{[20-23]}$ :

$$
\begin{aligned}
& \text { Plane: } \frac{G_{L}}{V} \geq \frac{-m C_{0}\left(1-k_{0}\right)}{k_{0} D_{L}} \\
& \text { Cell: } \frac{-m C_{0}\left(1-k_{0}\right)}{k_{0} D_{L}} \geq \frac{G_{L}}{V} \geq \frac{-m C_{0}\left(1-k_{0}\right)}{2 D_{L}} \\
& \text { Dendrite: } \frac{G_{L}}{V} \leq \frac{-m C_{0}\left(1-k_{0}\right)}{2 D_{L}}
\end{aligned}
$$

where $G_{L}\left({ }^{\circ} \mathrm{C} \cdot \mathrm{mm}^{-1}\right)$ stands for the liquid phase temperature gradient during solidification, $V\left(\mu \mathrm{m} \cdot \mathrm{s}^{-1}\right)$ stands for the solidification rate, $m\left({ }^{\circ} \mathrm{C} \cdot \%^{-1}\right)$ stands for the liquidus slope,
$D_{L}\left(\mathrm{~cm}^{2} \cdot \mathrm{s}^{-1}\right)$ stands for the diffusion coefficient of carbon in liquid phase, $k_{0}$ and $C_{0}(\%)$ are the equilibrium redistribution coefficient and mass fraction of carbon in the tested steel, respectively. The solidification parameters of Fe- $0.61 \% \mathrm{C}$ steel are given in Table $2^{[24]}$. It can be calculated that the values

of $\frac{-m C_{0}\left(1-k_{0}\right)}{k_{0} D_{L}}$ and $\frac{-m C_{0}\left(1-k_{0}\right)}{2 D_{L}}$ are $1.42 \times 10^{10}$ and

$2.34 \times 10^{9}{ }^{\circ} \mathrm{C} \cdot\left(\mathrm{s} \cdot \mathrm{m}^{2}\right)^{-1}$, while the ratio of temperature gradient and five solidification rates $\left(40,80,160,200\right.$ and $\left.320 \mu \mathrm{m} \cdot \mathrm{s}^{-1}\right)$ are $2 \times 10^{9}, 1 \times 10^{9}, 5 \times 10^{8}, 4 \times 10^{8}$ and $2.5 \times 10^{8}{ }^{\circ} \mathrm{C} \cdot\left(\mathrm{s} \cdot \mathrm{m}^{2}\right)^{-1}$, respectively. According to Eqs. (1)-(3), the morphology of the solid-liquid interface under five solidification rates are all dendrites, which are in good agreement with the experimental results shown in Fig. 2. 
Table 2: Solidification parameters of $\mathrm{Fe}-0.61 \% \mathrm{C}$ steel ${ }^{[24]}$

$\begin{array}{cccc}m\left({ }^{\circ} \mathrm{C} \cdot \%^{-1}\right) & D_{L}\left(\mathrm{~cm}^{2} \cdot \mathrm{s}^{-1}\right) & k_{0} & C_{0}(\%) \\ -73.3 & 6.4 \times 10^{-5} & 0.33 & 0.61\end{array}$

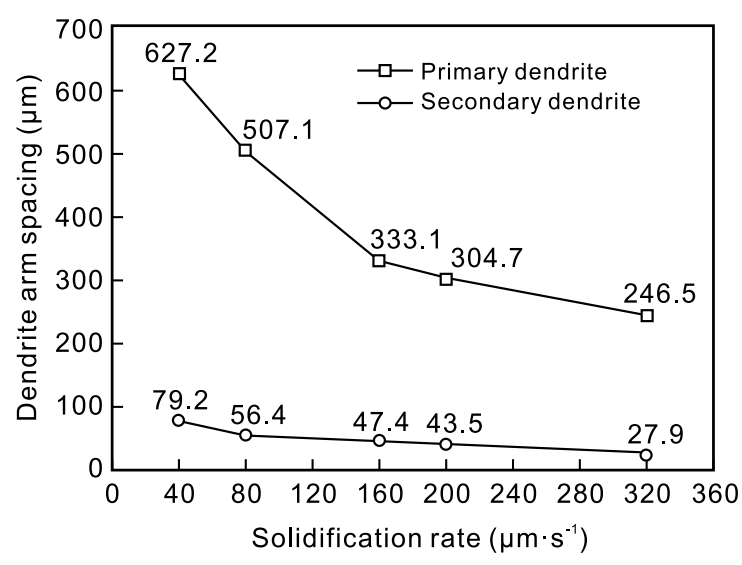

Fig. 3: Statistical results of dendrite arm spacing of Fe$0.61 \% \mathrm{C}$ steel under different solidification rates

Figure 3 shows the statistical results of dendrite arm spacing of $\mathrm{Fe}-0.61 \% \mathrm{C}$ steel under different solidification rates. It can be found from Fig. 3 that the primary and secondary dendrite arm spacings of $\mathrm{Fe}-0.61 \% \mathrm{C}$ steel under different solidification rates are in the range of 246.5-627.2 $\mu \mathrm{m}$ and 27.9-79.2 $\mu \mathrm{m}$, respectively. Moreover, both primary and secondary dendrite arm spacings show an obvious decreasing trend as the solidification rate increases from $40 \mu \mathrm{m} \cdot \mathrm{s}^{-1}$ to $320 \mu \mathrm{m} \cdot \mathrm{s}^{-1}$, which is attributed to the dendrite arm spacing being determined by heat dissipation condition, and is a monotone decreasing function of cooling rate ${ }^{[25]}$.

\subsection{Micro-segregation of carbon atoms at solid-liquid interface of $\mathrm{Fe}-0.61 \% \mathrm{C}$ steel}

Figure 4 shows the EPMA results of carbon contents at solidliquid interface of $\mathrm{Fe}-0.61 \% \mathrm{C}$ steel under different solidification rates by mapping. The area ratios of carbon contents in liquid (Area 1), solid-liquid (Area 2) and solid (Area 3) zone of $\mathrm{Fe}-0.61 \% \mathrm{C}$ steel under different solidification rates were calculated, as shown in Fig. 5. Figure 6 exhibits the EPMA results of carbon contents approximately along (Line 1) and perpendicular to (Line 2) the dendrite growth direction by line scanning (L: liquid phase, S: solid phase). It can be found from Fig. 4 that carbon atoms are rejected from dendrites and accumulate in the interdendritic melt due to solute redistribution at the solid-liquid interface. Furthermore, the average carbon content at the solid-liquid interface of $\mathrm{Fe}-0.61 \% \mathrm{C}$ steel with a solidification rate of $40 \mu \mathrm{m} \cdot \mathrm{s}^{-1}$ is significantly higher than those with other solidification rates, which indicates that a lower solidification rate promotes the enrichment of carbon atoms in the solid-liquid zone. There are two main causes to explain this result ${ }^{[15,26-28]}$. On the one hand, when the solidification rate is low, large dendrite spacing and a slow-moving dendritic interface create less resistance and more time for the migration of interdendritic carbon atoms to the liquid zone [Fig. 4(a)], which results in the continuous enrichment of carbon atoms to the liquid zone during solidification. Figure 6(a) shows that the carbon content at most points of solid-liquid interface of $\mathrm{Fe}-0.61 \% \mathrm{C}$ steel with a solidification rate of $40 \mu \mathrm{m} \cdot \mathrm{s}^{-1}$ almost exceeds that in the tested steel and the average values of carbon content in Line 1 and Line 2 are $0.658 \mathrm{wt} . \%$ and $0.930 \mathrm{wt} . \%$, while the maximum values of Line 1 and Line 2 reach $2.88 \mathrm{wt} . \%$ and $3.86 \mathrm{wt} . \%$. As the solidification rate increases, abundant and elongated secondary dendrite arms with small spacing seriously impede the diffusion of interdendritic carbon-rich melt to the liquid zone which can be demonstrated by the result that there is only obvious dendrite segregation but little difference in the carbon content among the Area 1, Area 2 and Area 3 of Fe- $0.61 \% \mathrm{C}$ steel with the highest solidification rates $\left(320 \mu \mathrm{m} \cdot \mathrm{s}^{-1}\right.$ in this study), as shown in Fig. 4(e) and Fig. 5. Moreover, the average values of carbon content in Line 1 and Line 2 of $\mathrm{Fe}-0.61 \% \mathrm{C}$ steel with a solidification rate of $320 \mu \mathrm{m} \cdot \mathrm{s}^{-1}$ are slightly lower than that in the tested steel, and the maximum values of Line 1 and Line 2 are reduced to $1.84 \mathrm{wt} . \%$ and $2.08 \mathrm{wt} . \%$, respectively. On the other hand, under a lower solidification rate, continuous enrichment of carbon atoms to liquid zone is more conducive to the decrease of liquidus temperature and the expansion of the solid-liquid temperature range which will further prolong the solidification time of molten steel. Furthermore, the amount of carbon atoms redistributing from the center of dendrite to the interdendritic region by the liquid $\rightarrow \gamma$ transformation under a lower solidification rate $\left(40 \mu \mathrm{m} \cdot \mathrm{s}^{-1}\right)$ is apparently more than that from the center of dendrite to the interdendritic region under a greater solidification rate $\left(320 \mu \mathrm{m} \cdot \mathrm{s}^{-1}\right)$, as shown in Fig. 6. As a result, after being pulled down $30 \mathrm{~mm}$, the area ratios of high-carbon content $(>0.61 \mathrm{wt} . \%)$ in the liquid, solid-liquid and solid zone of $\mathrm{Fe}-0.61 \% \mathrm{C}$ steel with a solidification rate of $40 \mu \mathrm{m} \cdot \mathrm{s}^{-1}$ achieve $91.5 \%, 84.8 \%$ and $81.2 \%$, while they are only $54.9 \%$, $46.3 \%$ and $39.1 \%$, respectively, with a solidification rate of $320 \mu \mathrm{m} \cdot \mathrm{s}^{-1}$, as shown in Fig. 5. It can be calculated from the carbon contents in Line 2 of Fig. 6 that the solid/liquid distribution coefficients of carbon in the austenite phase of $\mathrm{Fe}-0.61 \% \mathrm{C}$ steel under different solidification rates are approximately in the range of $0.1-0.2$, which are apparently smaller than the solid/liquid equilibrium distribution coefficient $k_{\mathrm{C}}$ shown in Fig. 1.

The directionally solidified microstructure of $\mathrm{Fe}-0.61 \% \mathrm{C}$ steel under different solidification rates is typical dendritic microstructure and the secondary dendrite arm spacings are only $27.9-79.2 \mu \mathrm{m}$. Since the secondary dendrite size is very small, it can be considered that the carbon diffusion in the liquid phase is uniform. In the case of back-diffusion, the carbon concentration in the solid phase of solid-liquid interface $\left(C_{\mathrm{S}}\right)$ is usually calculated by the Eq. (4) based on B-F model ${ }^{[2]}$.

$$
C_{\mathrm{S}}=k_{0} C_{0}\left[1-\left(1-2 a k_{0}\right) f_{\mathrm{S}}\right]^{\frac{k_{0}-1}{1-2 a k_{0}}}
$$

In Eq. (4), $f_{\mathrm{S}}(\%)$ stands for the volume fraction of solid phase, $a$ is the Fourier number which determines the back 


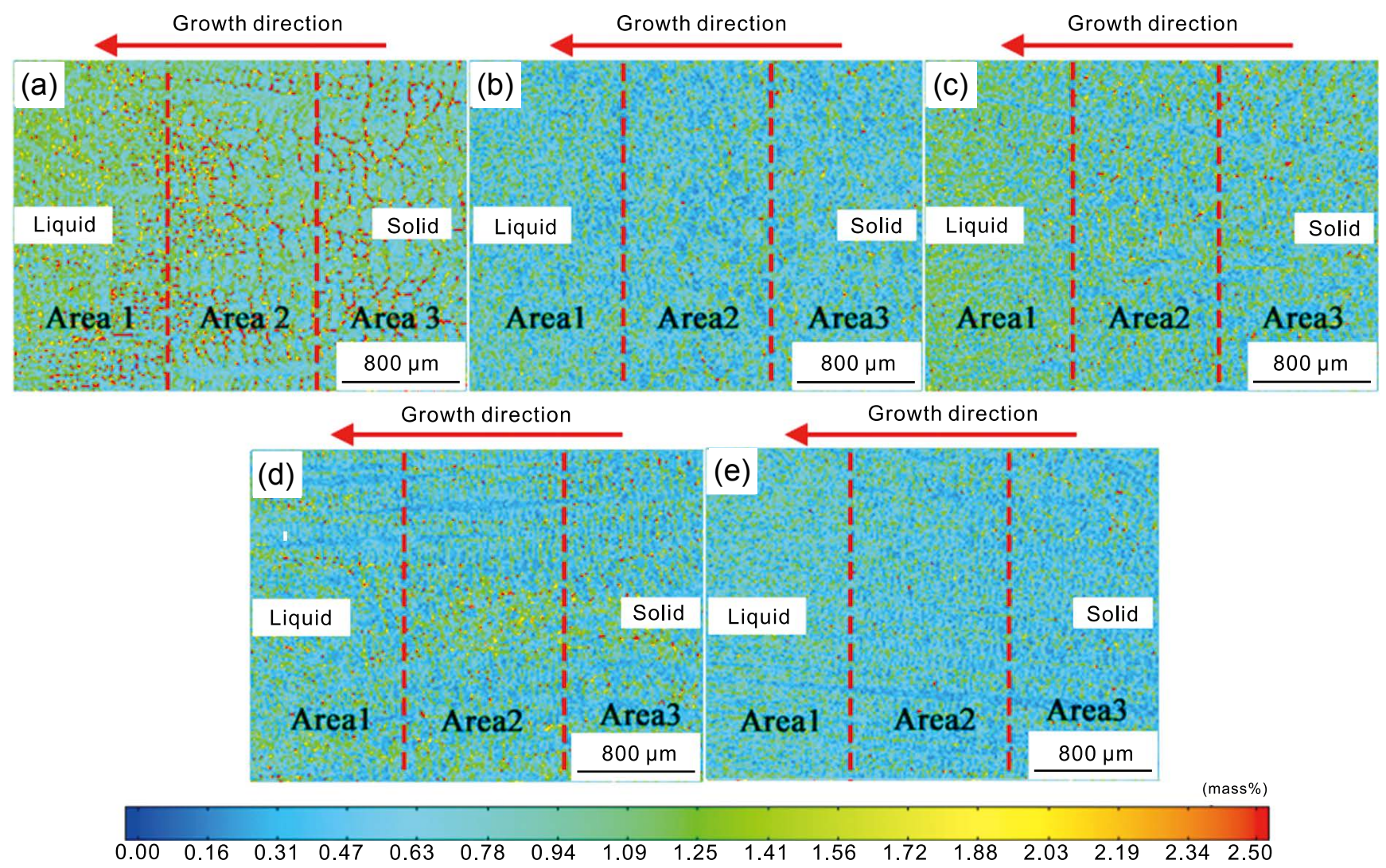

Fig. 4: EPMA images of carbon contents at solid-liquid interface of $\mathrm{Fe}-0.61 \% \mathrm{C}$ steel under different solidification rates by mapping: (a) $40 \mu \mathrm{m} \cdot \mathrm{s}^{-1}$; (b) $80 \mu \mathrm{m} \cdot \mathrm{s}^{-1}$; (c) $160 \mu \mathrm{m} \cdot \mathrm{s}^{-1}$; (d) $200 \mu \mathrm{m} \cdot \mathrm{s}^{-1}$; (e) $320 \mu \mathrm{m} \cdot \mathrm{s}^{-1}$
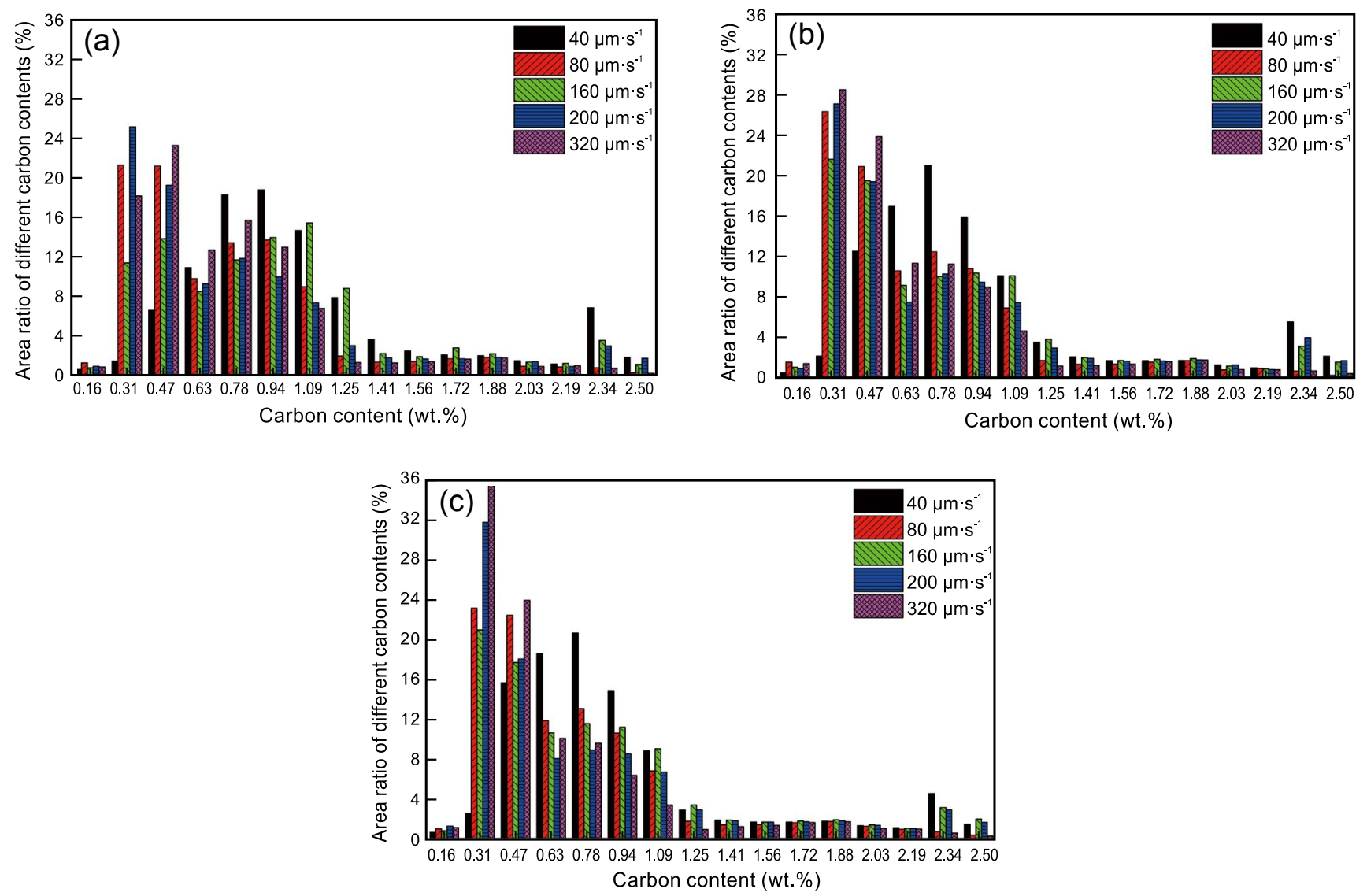

Fig. 5: Area ratios of carbon contents in liquid (a), solid-liquid (b) and solid (c) zone of Fe- $0.61 \% \mathrm{C}$ steel under different solidification rates 


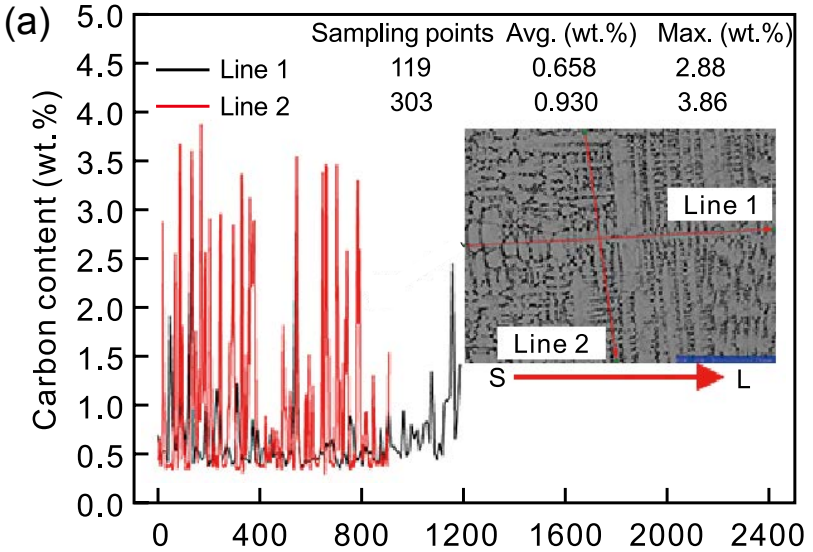

Distance from beginning of line scanning $(\mu \mathrm{m})$

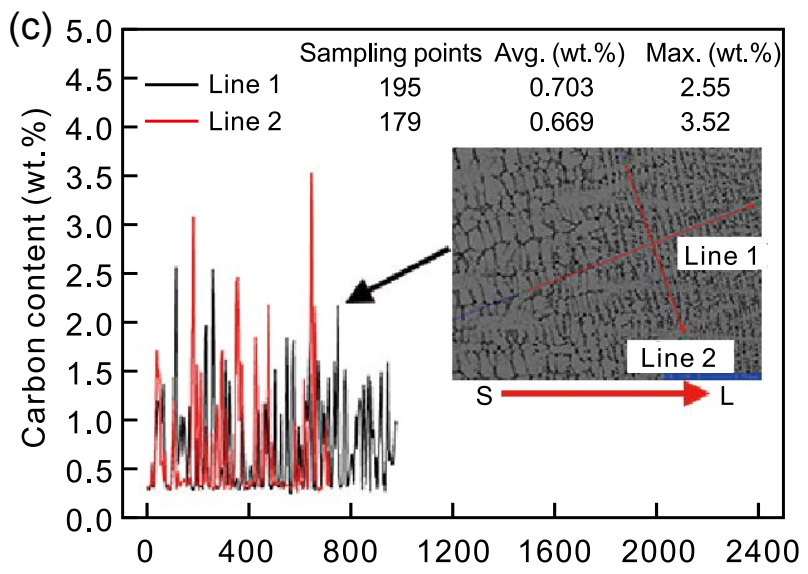

Distance from beginning of line scanning $(\mu \mathrm{m})$

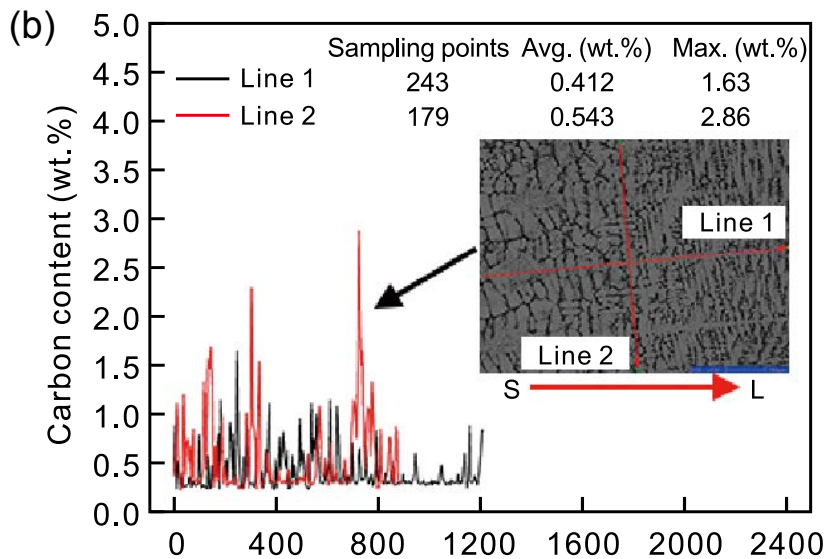

Distance from beginning of line scanning $(\mu \mathrm{m})$

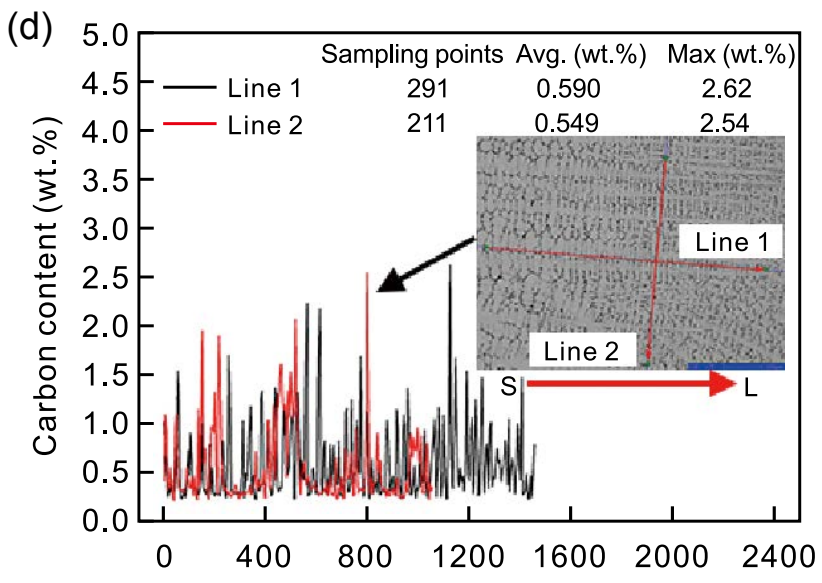

Distance from beginning of line scanning $(\mu \mathrm{m})$

(e)

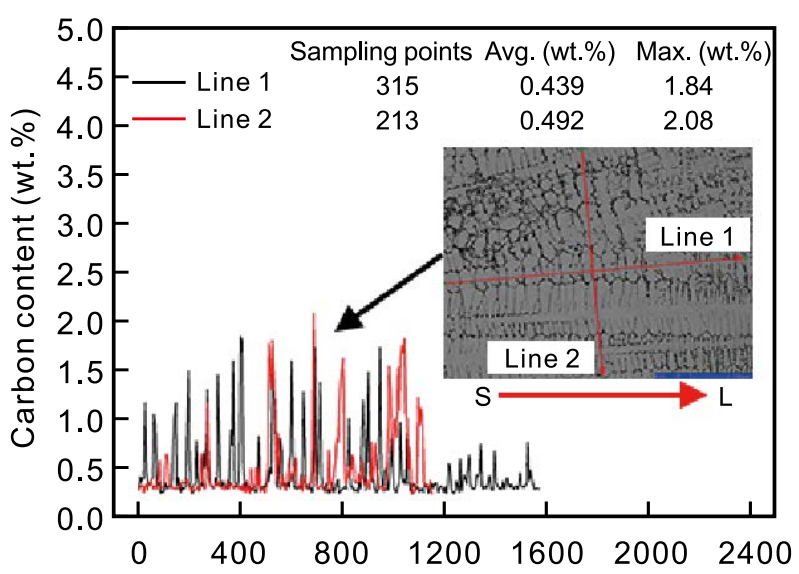

Distance from beginning of line scanning $(\mu \mathrm{m})$

Fig. 6: EPMA results of carbon contents in solid-liquid zone of $\mathrm{Fe}-0.61 \% \mathrm{C}$ steel under different solidification rates by line scanning approximately along (Line 1) and perpendicular to (Line 2) dendrite growth direction: (a) $40 \mu \mathrm{m} \cdot \mathrm{s}^{-1}$; (b) $80 \mu \mathrm{m} \cdot \mathrm{s}^{-1}$; (c) $160 \mu \mathrm{m} \cdot \mathrm{s}^{-1}$; (d) $200 \mu \mathrm{m} \cdot \mathrm{s}^{-1}$; (e) $320 \mu \mathrm{m} \cdot \mathrm{s}^{-1}$

diffusion degree of carbon atom in the solid phase and can be expressed by Eq. (5):

$$
a=D_{\mathrm{S}} \frac{\tau}{l^{2}}=D_{0} \exp \left(\frac{Q}{k T}\right) \frac{\tau}{l^{2}}
$$

where, $D_{S}$ and $D_{0}\left(\mathrm{~cm}^{2} \cdot \mathrm{s}^{-1}\right)$ are the diffusion coefficient and diffusion constant of carbon atom in solid phase, $k$ is the Boltzmann constant, $Q(\mathrm{~J})$ is the diffusion activation energy of carbon, $T(\mathrm{~K})$ is the Kelvin temperature, $\tau(\mathrm{s})$ is the diffusion time, $l(\mathrm{~cm})$ is the diffusion distance.

It is well known that the increase of solidification rate will cause the temperature of steel to drop too fast during solidification, thus making the diffusion time of carbon atoms shorter and dendrite spacing smaller. It can be seen from Eq. (5) that the decrease of back-diffusion time is not conducive to the back-diffusion of carbon atom, while the decrease of dendrite 
spacing will shorten the back-diffusion distance which is beneficial to the back-diffusion of carbon atom. When the solidification rate is low, the effect of increasing solidification rate on reducing carbon back-diffusion time is noticeably greater than that on the reduction of dendrite spacing, which will weaken back-diffusion of carbon atom between adjacent dendrites and result in the intensification of dendrite segregation. However, a greater cooling rate is more conducive to refining primary and secondary dendrites and shortening the back-diffusion distance of carbon atoms which will clearly strengthen the interaction of carbon diffusion field between adjacent dendrites and make the distribution of carbon atoms more uniform. As a result, with the increase of solidification rate, the difference of carbon content between dendrite arm and interdendrite decreases significantly, but the carbon content is lower at solidification rate of $80 \mu \mathrm{m} \cdot \mathrm{s}^{-1}$ than that at solidification rate of 160 and $200 \mu \mathrm{m} \cdot \mathrm{s}^{-1}$, as shown in Fig. 6 .

(a)

\subsection{Quenching microstructure and Vickers hardness of $\mathrm{Fe}-0.61 \% \mathrm{C}$ steel under different solidification rates}

Figure 7 exhibits the sampling position and quenching microstructures of solid-liquid zone, solid zone, and stable growth zone of $\mathrm{Fe}-0.61 \% \mathrm{C}$ steel under different solidification rates. Figure 8 displays the Vickers hardness along the central axis of the longitudinal section of directionally solidified samples with different solidification rates after quenching. It can be seen from Figs. 7(b) and (c) that the quenching microstructures in the solid-liquid and solid zone of Fe$0.61 \% \mathrm{C}$ steel under solidification rates of $40 \mu \mathrm{m} \cdot \mathrm{s}^{-1}$ and $80 \mu \mathrm{m} \cdot \mathrm{s}^{-1}$ are characterized by a considerable amount of fine acicular martensite (marked with arrows), in conjunction with a small amount of residual austenite, while the quenching microstructure in the stable growth zone of the $\mathrm{Fe}-0.61 \% \mathrm{C}$ steel transforms into fine acicular martensite. As solidification rate increases to $160 \mu \mathrm{m} \cdot \mathrm{s}^{-1}, 200 \mu \mathrm{m} \cdot \mathrm{s}^{-1}$ and then to $320 \mu \mathrm{m} \cdot \mathrm{s}^{-1}$,
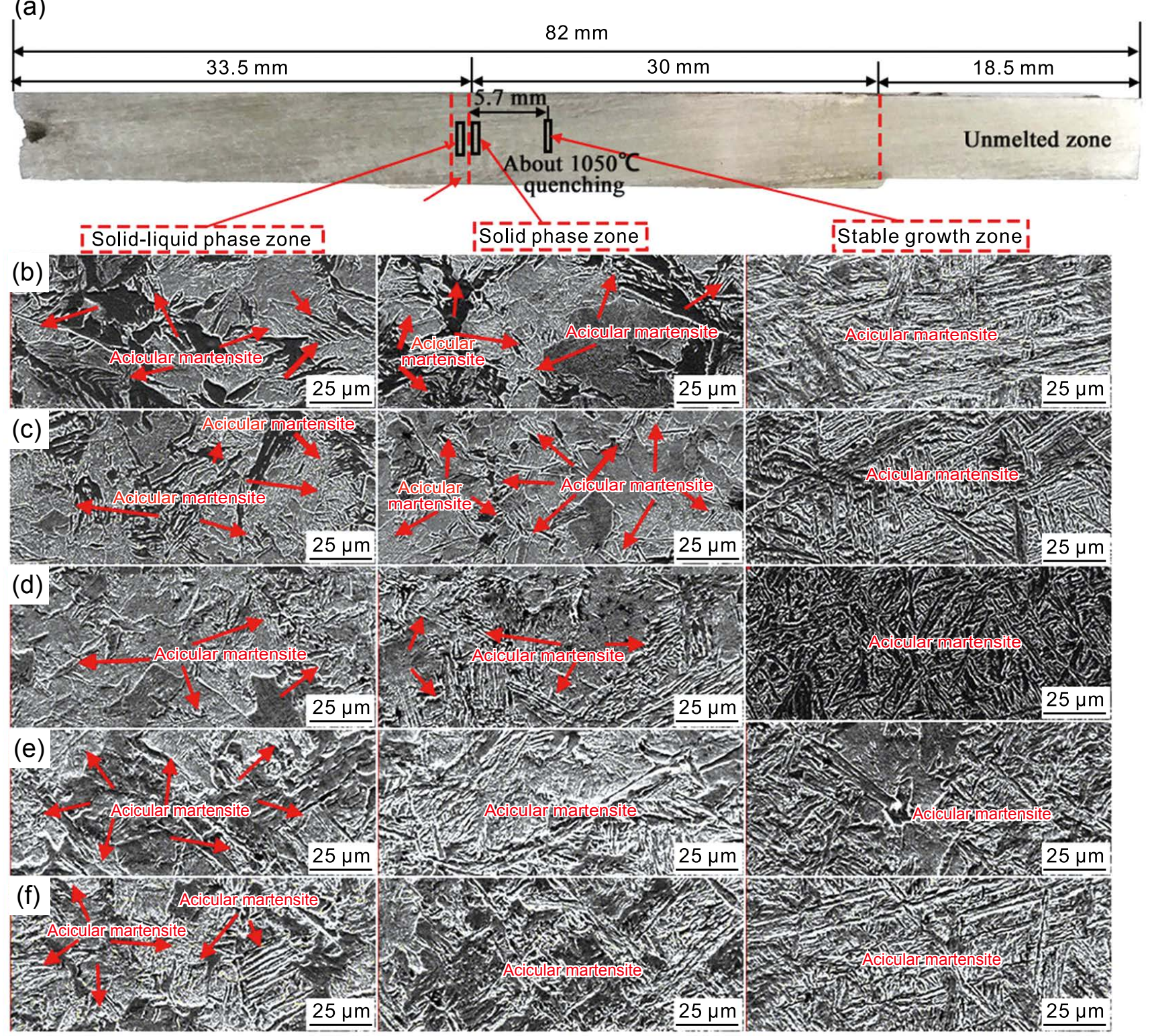

Fig. 7: Sampling position (a) and quenching microstructures of solid-liquid, solid zone, and stable growth zone of Fe-0.61\%C steel with solidification rates of $40 \mu \mathrm{m} \cdot \mathrm{s}^{-1}$ (b), $80 \mu \mathrm{m} \cdot \mathrm{s}^{-1}$ (c), $160 \mu \mathrm{m} \cdot \mathrm{s}^{-1}$ (d), $200 \mu \mathrm{m} \cdot \mathrm{s}^{-1}$ (e) and $320 \mu \mathrm{m} \cdot \mathrm{s}^{-1}$ (f), respectively 


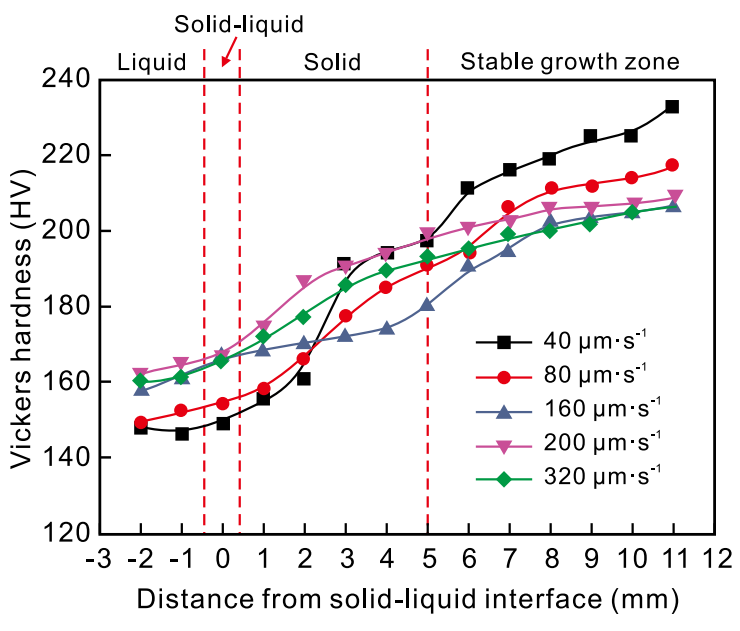

Fig. 8: Vickers hardness of $\mathrm{Fe}-0.61 \% \mathrm{C}$ steel under different solidification rates after quenching

the quenching microstructures in the solid-liquid, solid zone, and stable growth zone of $\mathrm{Fe}-0.61 \% \mathrm{C}$ steel are mainly fine acicular martensite (marked with arrows), as shown in Fig. 7(d-f). It is well known that the decrease of solidification rate is beneficial to prolong the residence time of the steel in the austenite temperature range, which is more conducive to the preservation of the quenched residual austenite ${ }^{[30-32]}$. Meanwhile, higher carbon content, such as exceeding $0.6 \mathrm{wt} . \%$, is more beneficial to stabilize austenite and reduces the final transformation temperature of martensite. Therefore, the solidliquid and solid zones of $\mathrm{Fe}-0.61 \% \mathrm{C}$ steel with higher carbon content and lower solidification rate more easily maintain the original austenite after quenching to room temperature. The appearance of residual austenite will reduce the hardness of the matrix. As a result, the hardness of those zones with solidification rates of $160 \mu \mathrm{m} \cdot \mathrm{s}^{-1}, 200 \mu \mathrm{m} \cdot \mathrm{s}^{-1}$ and $320 \mu \mathrm{m} \cdot \mathrm{s}^{-1}$ is significantly higher than those with solidification rates of $40 \mu \mathrm{m} \cdot \mathrm{s}^{-1}$ and $80 \mu \mathrm{m} \cdot \mathrm{s}^{-1}$, as shown in Fig. 8. However, the hardness of quenched stable growth zone with solidification rates of $40 \mu \mathrm{m} \cdot \mathrm{s}^{-1}$ and $80 \mu \mathrm{m} \cdot \mathrm{s}^{-1}$ seems higher than those zones with solidification rates of $160 \mu \mathrm{m} \cdot \mathrm{s}^{-1}, 200 \mu \mathrm{m} \cdot \mathrm{s}^{-1}$ and $320 \mu \mathrm{m} \cdot \mathrm{s}^{-1}$. This is probably because a high solidification rate causes the stability of austenite to deteriorate during solidification phase transition, thus reducing the hardenability of steel.

\section{Conclusions}

The effect of solidification rates $\left(40,80,160,200\right.$ and $\left.320 \mu \mathrm{m} \cdot \mathrm{s}^{-1}\right)$ on the solid-liquid interface morphology, micro-segregation of carbon and quenching microstructure of $\mathrm{Fe}-0.61 \% \mathrm{C}$ steel was fully studied. The obtained results are as follows:

(1) At a high temperature gradient of $80^{\circ} \mathrm{C} \cdot \mathrm{mm}^{-1}$, with solidification rate increasing from $40 \mu \mathrm{m} \cdot \mathrm{s}^{-1}$ to $320 \mu \mathrm{m} \cdot \mathrm{s}^{-1}$, the solid-liquid interface morphologies of $\mathrm{Fe}-0.61 \% \mathrm{C}$ steel are all typical dendrites, and the primary and secondary dendrite arm spacings gradually decrease from $627.2 \mu \mathrm{m}$ and $79.2 \mu \mathrm{m}$ to $246.5 \mu \mathrm{m}$ and $27.9 \mu \mathrm{m}$, respectively.
(2) With solidification rate increasing from $160 \mu \mathrm{m} \cdot \mathrm{s}^{-1}$ to $320 \mu \mathrm{m} \cdot \mathrm{s}^{-1}$, the difference of carbon content between dendrite arm and interdendrite decreases significantly. Compared with other solidification rates, the average carbon content at solidliquid interface of $\mathrm{Fe}-0.61 \% \mathrm{C}$ steel with a solidification rate of $40 \mu \mathrm{m} \cdot \mathrm{s}^{-1}$ is significantly higher.

(3) When solidification rates are $40 \mu \mathrm{m} \cdot \mathrm{s}^{-1}$ and $80 \mu \mathrm{m} \cdot \mathrm{s}^{-1}$, an amount of residual austenite appears in the quenching solidliquid and solid zone which results in a decrease in hardness of matrix. As solidification rate increases to $160 \mu \mathrm{m} \cdot \mathrm{s}^{-1}, 200 \mu \mathrm{m} \cdot \mathrm{s}^{-1}$ and then to $320 \mu \mathrm{m} \cdot \mathrm{s}^{-1}$, the quenching microstructures in the solid-liquid, solid zone, and stable growth zone of $\mathrm{Fe}-0.61 \% \mathrm{C}$ steel are fine acicular martensite. Furthermore, the hardness of the quenched stable growth zone with solidification rates of $40 \mu \mathrm{m} \cdot \mathrm{s}^{-1}$ and $80 \mu \mathrm{m} \cdot \mathrm{s}^{-1}$ seems higher than those zones with solidification rates of $160 \mu \mathrm{m} \cdot \mathrm{s}^{-1}, 200 \mu \mathrm{m} \cdot \mathrm{s}^{-1}$ and $320 \mu \mathrm{m} \cdot \mathrm{s}^{-1}$.

\section{Acknowledgements}

The authors gratefully acknowledge support from the State Key Laboratory of Refractories and Metallurgy (Wuhan University of Science and Technology) (Grant No. G201902) and the National Natural Science Foundation of China (Grant Nos. 51874001, U1760108).

\section{References}

[1] Raihle C M, Fredriksson $\mathrm{H}$. On the formation of pipes and centerline segregates in continuously cast billets. Metallurgical and Materials Transactions B, 1994, 25(1): 123-133.

[2] Yamazaki M, Natsume $Y$, Harada H. Numerical simulation of solidification structure formation during continuous casting in Fe-0.7 mass\% C alloy using cellular automaton method. ISIJ International, 2006, 46(6): 903-908.

[3] Zeng J, Chen W Q. Effect of casting speed on solidification structure and central macrosegregation during continuous casting of high-carbon rectangular billet. Metallurgia Italiana, 2015, 107(7): 43-50.

[4] Stercken K. Aspects of center segregation in high-carbon wire rod rolled from continuously cast billets. In: Proceedings of the International Symposium on Near-Net-Shape Casting in the Minimills, Vancouver, BC, Canada, 19-3 August 1995: 163-177.

[5] Boue-Bigne F. Simultaneous characterization of elemental segregation and cementite networks in high carbon steel products by spatially-resolved laser-induced breakdown spectroscopy. Spectrochimica Acta Part B: Atomic Spectroscopy, 2014, 96: 21-32.

[6] Wang S U, Wang W L, Luo S, et al. Heat transfer and central segregation of continuously cast high carbon steel billet. Journal of Iron and Steel Research, International, 2014, 21(6): 565-574.

[7] Chu R S, Li Z J, Liu J G, et al. Effect of soft reduction process on segregation of a $400 \mathrm{~mm}$ thick high-alloy steel slab. Journal of Iron and Steel Research International, 2021, 28(3): 272-278.

[8] Zeng J, Chen W Q, Zhang S L, et al. Development and application of final permanent magnet stirring during continuous casting of high carbon rectangular billet. Transactions of the Iron \& Steel Institute of Japan, 2015 55(10): 2142-2149 
[9] Nicholas Grundy A, Münch S, Feldhaus S, et al. Continuous casting of high carbon steel: How does hard cooling influence solidification, micro- and macro segregation. IOP Conference Series: Materials Science and Engineering, 2019, 529(1): 12069-12069.

[10] Beckermann C. Modelling of macrosegregation: Applications and future needs. International Materials Reviews, 2002, 47(5): 243-261.

[11] Eskin D G, Nadella R, Katgerman L. Effect of different grain structures on centerline macrosegregation during direct-chill casting. Acta Materialia, 2008, 56(6): 1358-1365.

[12] Zeng J, Chen W Q. Effect of secondary cooling conditions on solidification structure and central macrosegregation in continuously cast high-carbon rectangular billet. High Temperature Materials \& Processes, 2015, 34(6): 577-583.

[13] Wan Y, Li M H, Chen L J, et al. Effect of final electromagnetic stirring parameters on central cross-sectional carbon concentration distribution of high carbon square billet. Metals, 2019, 9(6): 665.

[14] Jiang D B, Zhu M Y. Center segregation with final electromagnetic stirring in billet continuous casting process. Metallurgical and Materials Transactions B, 2017, 48(2): 444-455.

[15] Jiang D B, Zhu M Y. Solidification structure and macrosegregation of billet continuous casting process with dual electromagnetic stirrings in mold and final stage of solidification: A numerical study. Metallurgical and Materials Transactions B, 2016, 47(12): 3446-3458.

[16] Shen Y Z, Yang S F, Liu J H, et al. Study on micro segregation of high alloy Fe-Mn-C-Al steel. Steel Research International, 2019, 90(5): 1800546.

[17] Wan $Y$, Feng K K, Zhao Q Q, et al. Effects of Al content and solidification rate on the crystal orientation of directionally solidified $1.3 \mathrm{wt} \%$ Si non-oriented electrical steel. Materials Research Express, 2019, 6(11): 1165b4.

[18] Flemings M C. Our understanding of macrosegregation: Past and present. ISIJ international, 2000, 40(9): 833-841.

[19] Krauss G. Solidification, segregation, and banding in carbon and alloy steels. Metallurgical and Materials Transactions B, 2003, 34(6): 781-792.

[20] Zhou Y H, Hu Z Q, Jie W Q. Solidification technology. Beijing: Mechanical Industry Press, 1998. (In Chinese)
[21] An G Y, Liu L X. Stability criterion of cellular interface. Metal Science \& Technology, 1985, 4(4): 55-64. (In Chinese)

[22] Lesoult G. Fundamental aspects of the solidification of steels. Ecoles des Mines Nanay, 1982. (In French)

[23] Rutter J W, Chalmers B. A prismatic substructure formed during solidification of metals. Canadian Journal of Physics, 1953, 31(1): 15-39.

[24] Chen J X. Data manual for charts commonly used in steelmaking (Version 2). Beijing: Metallurgical Industry Press, 2010. (In Chinese)

[25] Trivedi R. Theory of dendritic growth during the directional solidification of binary alloys. Journal of Crystal Growth, 1980, 49(2): 219-232.

[26] Sun H B, Zhang J Q. Study on the macrosegregation behavior for the bloom continuous casting: Model development and validation. Metallurgical and Materials Transactions B, 2013, 45(3): 1133-1149.

[27] Choudhary S K, Ganguly S, Sengupta A, et al. Solidification morphology and segregation in continuously cast steel slab. Journal of Materials Processing Technology, 2017, 243: 312321.

[28] Chen H B, Long M J, Chen D F, et al. Numerical study on the characteristics of solute distribution and the formation of centerline segregation in continuous casting (CC) slab. International Journal of Heat \& Mass Transfer, 2018, 126(Part A): 843-853.

[29] Kurz W, Fisher D J. Fundamentals of solidification. 4th Ed., Switzerland: Trans Tech Publication Ltd., 1998: 123.

[30] Amini K, Nategh S, Shafyei A, et al. Effect of deep cryogenic treatment on the properties of $80 \mathrm{CrMo} 125$ tool steel. Journal of Mineral Metallurgy and Materials, 2012, 19(1): 30-37.

[31] Hao Q G, Qin S W, Liu Y, et al. Effect of retained austenite on the dynamic tensile behavior of a novel quenching-partitioningtempering martensitic steel. Materials Science and Engineering A, 2016, 662: 16-25.

[32] Liu Y F, Peng Y, Liu H M, et al. Modeling of $Y \rightarrow a$ transformation temperature Ar3 for high-Nb pipeline steel during cooling process. Journal of Iron and Steel Research International, 2011, 18(7): 59-63. 